\title{
Comparison between two methods of measuring the grazing time of ewes
}

\author{
G Béchet, JP Brun, M Petit
}

INRA, Laboratoire Adaptation des Herbivores aux Milieux, Theix, 63122 St-Genès-Champanelle, France

Two methods to measure daily grazing time of ewes were compared : the first method used a portable electronic device (APEC : Brun JP et al, 1984, 5th Meet Eur Grazing Workshop), and the second used visual observations.

The APEC weighs $270 \mathrm{~g}$ and is fitted with $4 \times 1.5$ volt batteries allowing 5 days' autonomous use. A rubber pear-shape, filled with foam, is fixed by a halter under the animal's mouth and is connected by a flexible pipe to the apparatus. The jaw movements produce pneumatic pulses which are received by a pressure transducer and converted into a numerical signal, (0) indicating no jaw movement, or (1) indicating at least one jaw movement. A microprocessor then stores the data on a $2.5 \mathrm{~s}$ time basis. The successive periods with the same state, are summed up and stored in memory. At the end of the recording session, the computer produces an output file made of successive sums of alternately inactive and active periods. A program translates this file into mastication time for grazing or rumination (Béchet $G$ et al, 1989, Small Ruminant Research, 2, 119-132).

In each of two groups of 12 ewes, grazing a cocksfoot pasture, five ewes (2 dry and 3 suckling twins) were fitted with an APEC in May, and five others in June. During one day in each period, individual grazing (standing with head down) was recorded every 10 minutes from dawn to dusk, i.e. for 15 and 17.5 hours respectively. Sixteen pairs of reliable results were obtained, 4 files from APEC having been unusable. Daily grazing time (GT) was longer in lactating than in dry ewes $(P<0.01)$, and increased (not significantly) from May to June. Average GT during daylight obtained by visual
(GTV) or electronic (GTE) recordings were not significantly different, whatever the period and physiological status of the ewes (table). However the relative differences between individual GTV and GTE were $9.6 \%$ on average. Linear regression of GTV(min) on GTE(min) gave the following relationship :

$$
\begin{aligned}
& \text { GTV }=92( \pm 38.3)+0.763( \pm 0.098) \text { GTE } \\
& n=16 \\
& r s d=37.2 \\
& r^{2}=0.81
\end{aligned}
$$

Differences between the 2 methods can arise for various reasons. The APEC counts all jaw movements, including those out of grazing, for example licking or drinking. Visual scanning (in this case, every $10 \mathrm{~min}$ ) of the grazing activity can also lead to individual errors. On the one hand, ewes could have been observed standing with head down while they were only choosing or searching for grass without jaw movement, and on the other hand, ewes could have been seen with head up while they were in fact finishing mastication. The first type of error could explain the greatest differences observed here in 2 dry ewes (GTV - GTE $=+76$ and $+51 \mathrm{~min}$ ), the second type the difference observed in 2 suckling ewes (-62 and $-73 \mathrm{~min})$.

In conclusion, the two methods give, on average, similar results, except in some individual cases because they do not register exactly the same components of behaviour. The APEC has the advantage of recording night grazing (here $20 \mathrm{~min}$ on average) and of sparing tedious observations. It is also able to make up to four successive nycthemeral recordings, although its working reliability remains uncertain under field conditions.

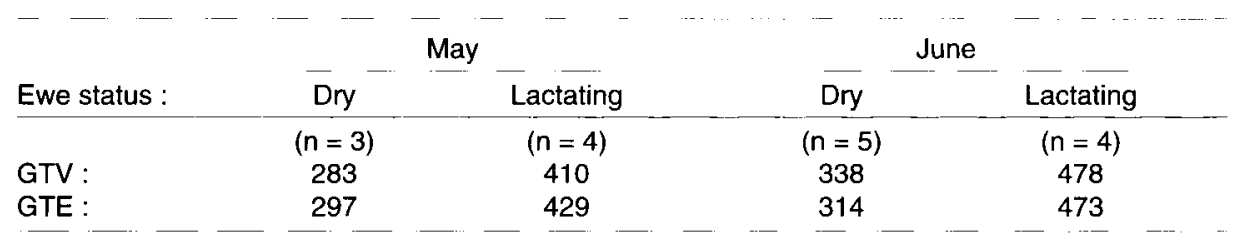

